\title{
IMMERSION THROUGH CULTURE: REPRESENTATIONS OF THE “DAY OF THE DEAD” IN FILM
}

\author{
Giorgos Dimitriadis \\ Aristotle University of Thessaloniki, Greece
}

\begin{abstract}
The Mexican celebration of the "Day of the Dead" (Día de Muertos or Día de los Muertos) has been recurrently used in film, with three of the most notable examples ranging from the recent Coco (Lee Unkrich and Adrian Molina, 2017) and Spectre (Sam Mendes, 2015), all the way back to the surviving footage of ; Que Viva Mexico! (Sergei Eisenstein, 1931, unfinished). Though vastly different from one another in almost every respect, all three cases explore the topic of "in-between" both thematically and technically: the celebration that merges life and death becomes a visual metaphor and a tool for filmmakers to explore the ways in which film technique creates overlapping areas between cinema and reality. In each film, a visually powerful cultural asset such as the "Day of the Dead," is combined with different aspects of film technique, explicitly, but differently, appealing to a kind of sensory immersion in order to attract viewers inside its world. By doing so, the "Day of the Dead" exemplifies the ways in which a common cultural element can help translate the personal visions of different filmmakers into distinct filmic events.
\end{abstract}

KeYwords: Immersion, Film, Montage, Long Take, Animation, "Day of the Dead," Que Viva Mexico, Spectre, Coco.

\section{INMERSIÓN CULTURAL: REPRESENTACIONES \\ DEL “DÍA DE MUERTOS” EN FILMES}

\section{RESUMEN}

La celebracion mejicana del "Día de muertos" ha sido utilizada repetidamente en el cine, con tres ejemplos muy conocidos que van desde las recientes Coco (Lee Unkrich and Adrian Molina, 2017) y Spectre (Sam Mendes, 2015), hasta la clásica escena que sobrevivió de ;Que Viva Mexico! (Sergei Eisenstein, 1931, inconclusa). Aunque muy diferentes en casi todos sus aspectos, las tres exploran el hallarse en un "limbo" tanto en el contenido como en la técnica: el gozo que surge de fusionar vida y muerte resulta para los directores una metáfora visual y una herramienta para indagar en el solapamiento entre cine y realidad. El "Día de muertos" (como demostración cultural visualmente poderosa) hace que en cada película se combinen diferentes técnicas fílmicas que explícitamente, pero de forma muy diversa, aluden a una inmersión sensorial que atrae a los espectadores a dicho reino. De este modo, el "Día de muertos" epitomiza las formas en las que un elemento cultural común puede ayudar a la traslación de las visiones personales de los directores en eventos fílmicos diferenciados.

Palabras ClaVe: Inmersión, filme, montaje, tomas largas, animación, "Día de muertos", Que Viva Mexico, Spectre, Coco.

DOI: https://doi.org/10.25145/j.recaesin.2020.81.05

Revista Canaria de Estudios Ingleses, 81; November 2020, pp. 61-78; ISSN: e-2530-8335 


\section{INTRODUCTION}

The level of engagement between viewers and the content of a film has been discussed extensively in film studies, acquiring yet another dimension in the context of culture. Often discussed as the level of immersion, it may refer to the ways in which the viewers' reality and the world of the film communicate with one another. Such an approach, wide as it may be, can offer insight into some of the reasons that enable the "Day of the Dead" (Día de Muertos or Día de los Muertos), a holiday with a strongly identifiable ethnic footprint, to become a recurring theme for films that are both chronologically distant and thematically diverse. It is not difficult to explain why the theme of the "Day of the Dead" has been used in cinema several times so far; the exuberance of its aesthetic wealth, the depth of its folklore and religious roots, and the weight of its references both to family ties and the ultimate human fate can easily serve as inspiration for films of different genres, eras, creative aspirations and target groups. The present article is a brief exploration of the ways in which these qualities of the "Day of the Dead" render it an experiential catalyst for the reality of viewers to cross paths with film watching; and in order to demonstrate the range of this ability that the "Day of the Dead" seems to possess, three entirely different films are selected: the surviving footage of ; Que Viva Mexico! (Sergei Eisenstein, 1931, unfinished), ${ }^{1}$ Spectre (Sam Mendes, 2015) and Coco (Lee Unkrich and Adrian Molina, 2017). The selection of these particular films aims at highlighting the inspirational potentials that a traditional, ethnic holiday is capable of carrying, especially when it is attached to a modern art form with an international scope, such as cinema.

The starting point for discussing the "Day of the Dead" in film is its ability to expand and affect people outside its originally Mexican borders. The film industry, not known for shifting its attention to indifferent or meaningless things, takes advantage of this exact resonance that the holiday has, not only among the general Latinx population in the US, but also Anglos or even international audiences that film distribution is capable of reaching. Even since the earlier days of cinema, projects, such as Eisenstein's for instance, attempted to use the dynamics of this holiday to explore the idea of change, regeneration and diachronicity by comprehending those dynamics in contexts that, indeed, on one hand encompass the strictly Mexican one, but on the other they are also capable of expanding even further, both geographically

${ }^{1}$ Citing and dating ; Que Viva Mexico! is a remarkably challenging task, since the film never came to existence as a released film the way Eisenstein intended it. The version of the film which is probably the closest one to Eisenstein in historical terms was completed under this title in 1979 by Grigoriy Aleksandrov, his close associate during their time in Mexico, but even that version "can at best be regarded as a generalized notion of what Eisenstein may have intended" (O’Mahony 140). For reasons of economy, the present article uses the title to refer to the sum of Eisenstein's lengthy footage, and in particular to the part of that footage that features the "Day of the Dead." The citation and year (1931) also refer to this material, as it was during October 1931 that Eisenstein shot most of the Epilogue part of the movie, to which the "Day of the Dead" footage belongs (Salazkina 140-141). 
as well as ethnically. ${ }^{2}$ Concerning the other two films in relation primarily to the US, which is a significant market for the film industry, the "Day of the Dead" can be discussed both in terms of its status as a strengthening factor for both a specifically Mexican as well as a pan-Latinx ethnic identity (Brandes 194), as well as aiming at "asserting a positive Latino presence in the US public sphere" (Marchi 2): although people of Mexican descent represent $60 \%$ of the US Latinx population and the holiday has been generally associated with Mexico, it is a tradition in other Latin American countries as well, made known in the US through the work of Chicanx artists, who "provided the artistic and ritual framework for others to participate in the celebration" (2-3). The weight of this information, combined with the increasing popularity of the holiday even outside Latinx communities, echoes into cultural production, of which cinema is a significant part, in two ways: first of all, according to Regina M. Marchi, it is an indication that Latinidad (Latin-ness) defies assumptions that premodern traditions are being abandoned under the homogenizing influence of Western culture (4-5); and second, it is connected with the fact that the "massive demographic presence" of Latinx minority in the US. is now shaping mainstream pop culture production in the country (Aldama 3-4). Considering all this information together, it is probable that the flexibility in which the "Day of the Dead" expresses a wider Mexican, Chicanx and Latinx identity is based on the same features that allow the holiday, as an important cultural asset, to be transplanted with relative ease to the US cultural production in general, and gradually find its way to the much wider audiences that the film industry in particular is interested in.

Issues of identity related with the celebration of the "Day of the Dead" contribute to assessing its value as a cross-cultural experience. As it becomes apparent from the multiple times the specific cultural tradition has been utilized in film, its themes seem to be able to penetrate cultural, aesthetic, ideological, or other boundaries. The three movies based on the "Day of the Dead" presently selected are all aimed at wider audiences, without confining themselves to the cultural proprietors of the holiday, i.e. the strictly Mexican (geographically speaking) or the wider Chicanx and Latinx communities. These movies, therefore, borrow elements from the "Day of the Dead" in order to appeal to a much wider target group for various reasons, e.g. financial, ideological, or other; each of the three films selected for discussion utilizes some of the features from the "Day of the Dead," as discussed further down, and uses cinematic language and technique to translate those features into an immersive experience for viewers. Such experiences allow viewers to virtually cross the borders of their own culture into another one. Stephanie Schütze and Martha Zapata Galindo see the "redefinition of cultural borders through intercultural encounters" as one found in what they call "transcultural spaces, which connect different space-time venues even when distant

After all, Eisenstein's project came from his aspiration to complete a film in the West and it was his international status as a filmmaker that would have imbued the film, had it been completed, with a more global outlook. 
geographically and chronologically" (qtd. in Montes de Oca 95). Extending this statement to the cinematic experience, the use of the "Day of the Dead" in film exemplifies the way in which cinema can function as a contemporary vehicle for the migration of cultural elements, a kind of globalized techno-artistic surrogate for the physical migrations of the past.

\section{CINEMA, TRANSGRESSION AND THE "DAY OF THE DEAD”}

Understanding some of the essential characteristics of the "Day of the Dead" is an important step in also understanding its popularity as a theme in filmmaking, as well as the various technical ways in which it is featured in films. The feature of the holiday that is mainly of use here is the fact that, from its roots to the present, the "Day of the Dead" essentially celebrates the "in-between" in practically every sense of the term. For centuries, diverse geographical, ethnic, religious and cultural elements were welded together to produce what would consequently become an experiential fusion, with the elements of combination and integration overpowering those of clashing and exclusion. First of all, with regard to its origins, it is connected to rituals and folklore practices that combine pre-Columbian and Roman-Catholic traditions (Shujaa 358-359); over the past centuries, the "Day of the Dead" crystallized into an inclusive feast, a combined variant of the Roman-Catholic holidays of All Saints' Day and All Souls' Day on November 1 and 2 respectively (Brandes 6). In some central parts of Mexico specifically, an additional day is added to the holiday before November 1, but this extra day neither relates to, nor is recognized by the RomanCatholic church (Brandes 8); this demonstrates and further accentuates the inclusive nature of the holiday as a whole.

Second, in terms of its appearance, the "Day of the Dead" is in itself an artistically significant event. Its aesthetic origins in the work of José Guadalupe Posada, as well as Manuel Manilla and others before him (Brandes 61-62), are trademarks not only of the Mexicans' "undeniable fascination with skulls, skeletons, and other representations of death" (45), but of an essentially modernist practice: on one hand, Peter Wollen notes that the artistic value of Posada's work was recognized, albeit posthumously, by the circle of established modernist artists around Diego Rivera (qtd. in Brandes 62); and, on the other, William H. Beezley, Cheryl Martin and William E. French observe that his art was among the things that provided the common people with a kind of "popular resistance" (qtd. in Brandes 63). The result of this recognition is much more than a colorful celebration of the ties between this world and the assumed next one, which blends the vivid colors associated with life with the morbid black of death, rituals with art, and flowers with graves and plastic mementos: instead, such a mixture manages to translate the folk cultural element of "an almost irreverent, macabre confrontation with mortality" (Brandes 7) with the kind of art that serves the people by acquiring extensions of political significance through its recognition, and ultimate inclusion, in the realm of the ideologically charged artistic movement of modernism. 
Finally, and perhaps most importantly as well, the "Day of the Dead" celebrates an uncannily pleasant encounter of life and death in terms of emotion, as humor is in a tight embrace with morbidity. Stanley Brandes stresses that the holiday is essentially a defiant mocking of death itself (60) and that it is designed for the living rather than the dead (49). Laughing in the face of death in such a manner normally elicits contradictory emotional responses that may coexist in the same person at the same time. This is probably the most profound and elementary kind of blending that can exist, in relation to being human: the two extreme polarities of the human condition, being and not being, are meant to clash and, through that clash, produce an aesthetic result that may be translated to all kinds of significations, i.e. cultural, political, artistic, or other.

In its representations of the "Day of the Dead," film normally and extensively builds on these features; at the same time, one must not forget that film, for all its global expansion, remains a cultural, commercial and technological product with a significant part of its identity being related to the US in one way or the other. It is therefore justifiable to consider the representations of the "Day of the Dead" in film keeping the American film industry in mind as an aspect of the American culture at large. In the US, the "Day of the Dead" seems to be expanding geographically and does so beyond its Chicanx and Catholic origins (Agredano-Lozano 78) with significant variations from one community to the other and with its various celebrations being "generally contested events, creating new rivalries and reviving old ones" (Brandes 157). One noteworthy point of comparison is that some American variations seem to have shifted the nature of the holiday from a private, family affair, to a more social, communal and secular celebration (Marchi 1-2; Brandes 178; Agredano-Lozano 79-80). As Brandes notes, the apparent suppression of many of its religious elements in its US versions today can make the holiday "appear to be as much of a secular family affair as Thanksgiving and as devotional an occasion as the Fourth of July" (145). In fact, he adds, celebrations are often aimed at establishing or strengthening relationships other than familial ones, specifically with "one's friends, political allies, local neighborhood, or wider ethnic community," with political causes being particularly common (158). ${ }^{3}$ The affinities of such conditions to cinema work on several levels. First of all, film, especially in the US, is a commercial product of mass entertainment that normally aims at attracting wide audiences in order to remain profitable. Because of that, the movie industry favors a kind of entertainment that, even if it includes specific ethnic or cultural elements, does not exclude others from enjoying them, effectively also becoming a communal experience. In addition to that, the occasional utilization of film as a vehicle for passing some kind of message included in it, thus drawing politics and ideology closer to the film experience, is

${ }^{3}$ Making use of "Day of the Dead" celebrations for political reasons is not limited to the US, though, as similar occasions also take place in Mexico (Smith 57). Clara Irazábal and Grace R. Dyrness also note that religious festivities for the "Day of the Dead" along and across the Mexican-US border are "usually full of sociopolitical commentary, even if covertly" (364). 
a known reality practically since the beginning of the medium. Under this light, it is evident that both film-watching and "Day of the Dead" festivities seem to share common ground: they can both be seen as artistic expressions that serve as the basis for communal, cross-cultural experiences, occasionally carrying a political or ideological load as well.

Taking a step back and considering the "Day of the Dead" as an experiential holiday, in relation to cinema as an art that is also based to a great extent on emotion and experience, it is remarkable to realize how much these traits of in-betweenness described earlier resemble in several ways the transgressive experience of film viewers. In fact, celebrating the "Day of the Dead" presupposes a relatively solid belief in the afterlife and its occasional communication with the world of the living. Filmwatching, on the other hand, entails an experience of the filmic world that requires acceptance of its verisimilitude, at least for the duration of the film's runtime, effectively transferring viewers temporarily to an in-between situation in which they accept a kind of validity for the filmic world without surrendering the stability of their own reality. The following section discusses different aspects of this resemblance as it is technically manifested in entirely different films. The features of fluidity and deliberate blurring of boundaries between elements that are otherwise placed in contrast to one another are common in all three of them, and yet explored in remarkably different ways, thus making definitions of immersion more flexible and adaptable. This preoccupation with the "Day of the Dead" found in such diverse films effectively demonstrates the value of the holiday as a visual manifestation of the inclusive thematic polysemy in cinema as a whole.

\section{SERGEI EISENSTEIN'S CROSS-CULTURAL IMMERSION}

In his "Mexican adventure," as it was referred to by the American novelist Upton Sinclair (308), Sergei Eisenstein was fascinated by the Mexican landscape as well as the traditions and history of the area. In a story most of the details and background of which are well-known and documented, Eisenstein's venture to the West was to bring him in contact not only with the filmmaking practices of other countries, but also with artistic stimulation that drove him to create what would become an ill-fated, but still invaluable piece of film history. After his release from a contract with Paramount due to a discernible inability to find common ground between the two parties, which made any prospect of their cooperation in a new film rather unlikely, ${ }^{4}$ Eisenstein traveled to Mexico financed by Sinclair to create a film driven by his fascination for the country and its history. Part of the footage he gathered would produce a visual monument to the "Day of the Dead," imbued

${ }^{4}$ Mike O'Mahony describes several possible film projects that were discussed between Eisenstein and Paramount, none of which would eventually come to be, leading to the termination of his contract (130-133). 
with cinematic qualities that go well beyond the geographical or cultural limits of Mexico specifically.

Eisenstein's Mexican project is a quite complex topic both from an aesthetic as well as a historical viewpoint, even if its consideration is only limited to the final Epilogue section of its originally intended six-episode structure, for which the director shot scenes from the "Day of the Dead" festivities. For all the significance of Eisenstein's editing theories and skill, historical reasons will inevitably never allow what survives of this particular film to be seen in the form that he wanted it to have: Eisenstein was never given the opportunity to edit himself the exceptionally lengthy footage ${ }^{5}$ he shot in preparation of ; Que Viva Mexico!, and he was explicitly dismayed to see others' "senseless" attempts to do so (qtd. in Vassilieva 700). Nevertheless, the underlying assumptions behind Eisenstein's attitude towards editing are still present-albeit latent-in his aspirations while planning the film and shooting the footage, as revealed in his own surviving rough outline of the movie. ${ }^{6}$ In that outline, Eisenstein refers to the use of the "Day of the Dead" in the film as a "unity of death and life," and the wisdom of mocking death by actually enjoying the process of things passing and being replaced by other things, in a continuous "eternal circle" in which death and rebirth perpetually co-exist (252). The intended arrangement of the film's episodes is in itself a denotation of this circularity: the film would begin with the theme of death in the Prologue and then revisit it in the Epilogue, engaging the viewer in its circular, or as Masha Salazkina prefers to see it, spiral structure (140141). The film techniques that Eisenstein uses to best express these notions magnify the same elements that also enhance the diachronic and transcultural symbolisms of the "Day of the Dead."

The Epilogue features the "Day of the Dead" as its main element in order to capitalize on the holiday's primordial themes of life, death and regeneration that are not strictly or necessarily associated with religious practices. Many decades ago, Eisenstein apparently saw in the "Day of the Dead" extensions that Brandes believes are becoming more widely obvious in recent years: Brandes notes that globalization has caused the "Day of the Dead" today to acquire a "definite political meaning and ideological symbolism far beyond its original religious essence" on both sides of the Mexico-US border (14). Sidestepping the political shades that connect this usage of themes with the history of Mexico in particular, especially following the Revolution of 1910, what is presently suggested is that Eisenstein's artistic vision made use of the "Day of the Dead" in a way that denotes elements that are present

5 Despite the fact that, due to duplicate footage, the total time of original material was approximately six hours, Eisenstein shot close to a quarter of a million feet of film rushes with a runtime of approximately forty hours (Salazkina 1).

${ }^{6}$ O’Mahony mentions that Eisenstein was known for using scenarios only as "as little more than rough guides" while making his films, and cites Marie Seton's note that this outline, apart from its use in the film's production, was probably also meant "to appease Sinclair and the Mexican censors" (140). Nevertheless, the outline is still an invaluable source of information on how the director treated his subject matter and planned to proceed with the project. 
in the essence of the holiday itself, and, as such, have been carried along and made more visible in today's geographical, cultural and media-related transplanting of the holiday north of the Mexico-US border. Similar to the "Day of the Dead" having acquired today, at least partly, a more secular and social aspect in the US, Eisenstein was probably inspired by the secular extensions of the holiday as well: the permeating feature of achieving harmony through contrast, expressed in a constant embrace of antithetical features, connects the film with the spirit of the celebration as an all-encompassing occasion, similar to its transcultural perpetuation in the present day. It is this same feature that stubbornly refuses confinement: having expanded beyond both Mexico and the wider Latinx culture, this holiday is similarly used in the US today as a tool for teaching the "multiculturalism and ethnic diversity that prevail throughout the urban United States" (Brandes 134).

Despite the fact that Eisenstein never edited the surviving footage into a coherent film that would reflect his vision, Robert Robertson traces in that footage the driving force behind Eisenstein's ideas about montage: the power that contrasting, "arbitrarily chosen" elements have when brought together to collaborate through their juxtaposition to "an 'essential' ideological theme" (4). In this particular case, Eisenstein himself saw the composition of contrasting elements in the serape, the colored stripes of which symbolized multicultural contact, "violently contrasting" and yet held together harmoniously by the "unity of the weave;" as the various cultures in Mexico were held together through the centuries by the same "spirit and character," the director planned to utilize rhythm and music to denote the internal bond between them, thus also to hold together the intended Episodes of what was meant to be the final film (251). Specifically about the "Day of the Dead" sequence, viewers of what survives of the Epilogue see in that footage the same spirit of "inclusion through contrast" that characterized Eisenstein's stylistic and theoretical aspirations. Andrea Noble states that Eisenstein found a "proto-filmic quality" in Mexican social reality: the shocking juxtapositions otherwise achieved in editing were already there, without the need for the camera or editing to bring them to the surface (182). In other words, all Eisenstein had to do to denote harmony through contrast was simply to use the filmic language in ; Que Viva Mexico! in order to showcase the magnetism of existing cultural elements in a fascinating contrast to each other.

The same harmonious unity found in contrasting elements is also visible in the way Eisenstein makes use of the theme of skulls and skeletons. Eisenstein actually had an "early attraction" to them well before his trip to Mexico, even from the time he saw Georges Méliès's silent work for the first time (Chinita 187). Viewers that are culturally unfamiliar with the holiday might see in skeletons an unsettling reminiscence of their mortality, and this sudden awareness of the inevitability of death is a kind of engagement that may easily achieve the opposite of the desired escapism generally associated with film-watching. Eisenstein prominently uses closeups and deep focus when filming paper masks that represent skulls. Close-ups, apart from featuring an alarmingly intense proximity, also reveal the artificiality and temporality of the paper masks; by doing so, they accentuate the ability of fearlessly staring in the face of death as something not only funny, but also transient and 
defeated. With this technique, Eisenstein demonstrates his explicit intention for this scene to be a provocation and mocking of death (252). The close-ups further heighten the effect of the shots in which masks are removed, revealing smiling faces mostly of children, some of which look straight into the camera, representing an image of the force of life prevailing over death (Salazkina 144). The use of deep focus creates a visual contrast between the foreground and background, and the content of the shots is anything but static, presenting the scene "in constant movement" (144), this way visually validating the thematic contrast between life and death. This "valorization of the life force" in the visual symbolisms of the skeleton and skulls (Chinita 187), intensified and refigured through Eisenstein's technique as a Dionysian feast that stimulates the senses, 7 signals an eternal and essentially harmonious balance between the two elementary states of the human condition, represented by the living and the dead, therefore alluding to the inescapably inherent human fate which cannot but attract the attention of the viewers at a fundamentally existential level, and, as such, draw them inside the essence of the depicted scene.

The "Day of the Dead" episode is probably the most known and celebrated part of the unfinished ;Que Viva Mexico! In fact, in relation to acknowledging the role that media played in the preservation of the "Day of the Dead" until the present day (Marchi 1), it is important to mention that the circulation of stills from Eisenstein's footage around the world was quite impactful and is believed to have contributed considerably to the international recognition of the cultural significance of the holiday (Salazkina 139). The experience viewers have of the film's Epilogue, even in its unfinished state, is based on both film technique and content, placing emphasis on the concept of transgression. Eisenstein's venture to the West was to become a metaphor for artistic border-crossing: among the other elements he used in the film, the "Day of the Dead" was meant to demonstrate "a model for a (utopian) total synthesis and the overcoming of all class, race, and gender differences" (Salazkina 169). Taking advantage of visual themes from a holiday that flourishes on contradictions, Eisenstein intended to immerse audiences in his film-only a glimpse of which will unfortunately ever be seen-by an acute stimulation of their senses.

\section{REALISTIC ENGAGEMENT IN SAM MENDES'S LONG TAKE}

Eisenstein's unrealized creative vision in ;Que Viva Mexico! is one version of the ways in which cinematic immersion may be attained, but it is certainly not the only one. The expressive wealth of filmmaking techniques allows for similar goals to be achieved in diametrically opposite ways. It is therefore a challenging task to search for common ground between Eisenstein's intentionally clashing sensations and the

As much as the footage gives this impression in the form that it currently survives, it is worth stressing that Eisenstein intended to further enhance it by applying to this film his innovative ideas about the use of sound in movies (Robertson 102). 
smoothness of Sam Mendes's long takes. ${ }^{8}$ Nevertheless, the opening scene in Spectre, which features an impressive four-minute long take, most of which takes place during an elaborate representation of the "Day of the Dead" as a massive community feast, emerges as a perfect example of how immensely different filmmaking techniques may actually serve similar purposes. Considering Eisenstein as a theorist of montage and placing him opposite André Bazin, who was a proponent of the long take, David George Menard summarizes this difference between approaches to film style: "It is a determined fact that Eisenstein represents reality (i.e. reality is manipulated as art remains a pure constant), that is, reality is taken to art; while Bazin presents reality (i.e. it is the art that changes and never the reality), in other words, art is taken to reality." In Menard's view, and for all the considerable aesthetic differences between these distinct approaches to film style, connecting the film-watching experience to reality is, in one way or the other, obviously central in both of them.

The value of the long take as a cinematic device has received adequate critical attention so far, and Spectre, the $24^{\text {th }}$ installment of the James Bond franchise, is a clear example of the importance of effectively combining technique and content in filmmaking. Although there is no general agreement among directors or theorists as to what the long take achieves, its ability to draw attention to itself has often associated it in Hollywood with auteurism and high-profile productions (Udden 37-38). Although it is visually and technically distanced from any kind of visible editing, it also features an uncanny proximity with a kind of real-life experience, a "certain sort of realism" as Nicholas Bugeja calls it, that does not go by unnoticed. Donato Totaro identifies claims that the long take has generally been used in cinema either as an "emphatic device" at the beginning or closing of a film, or as a tool that draws attention to cinematic technologies for reasons of impression and overall effect. Both these purposes seem to be fulfilled in Spectre, as the opening scene aims at capitalizing on all the technical, production-related, aesthetic and narrative elements that it features: respectively, these are the successful impression of a continuous long take (although invisible editing of a sequence of shots was actually used), the star caliber of Daniel Craig as an already successful Bond from preceding films, and, most importantly, the prominence of the "Day of the Dead" as both an aesthetic and narrative theme. This theme helps create a lavish background for action and emphasizes the character's position, constantly being at the crossroad of life and death throughout the franchise.

The way in which the main character is re-asserted in the opening scene, which is not unusual in James Bond films, is provided in Spectre through an extravagant representation of a holiday that fuses the two extremes of the human condition, being alive vs. being dead. This polarity is established on screen right

8 Steve Neale defines long takes as shots that extend unusually longer than normal, compared to "historical or national norms" (28). Although easily spotted in a film, it is worth noting that there is no agreement, let alone any standardization, of the duration of long takes (Udden 42).

9 Emphasis in the original. 
away, with the sentence "the dead are alive" appearing on a black background right before the scene opens: first the phrase "the dead" appears, setting the tone for the scene, followed by a subversive and contradicting "are alive" after four seconds, right before a huge mechanical skeleton fills the screen parading in a massive "Day of the Dead" festival. In the rest of the scene, the camera follows Bond in a skeleton mask, marking his target and smoothly moving throughout the long take successively in the street, then inside the hotel, and, finally, through an open balcony door, on a rooftop, where he prepares to carry out an assassination. The camera allows viewers to follow Bond closely as he moves around the setting through open doors in a way that connotes an almost natural gliding between life and death: from the festive, vivid atmosphere in the crowded street and the beautiful woman waiting for him in the hotel room, to the loneliness of the rooftop as he gets closer to shooting his target.

It is obvious here that the essential theme of in-betweenness that the "Day of the Dead" encompasses is a thematic concern visually translated to cinematic technique. The long take has been widely appraised in terms of the effect it has on viewers, which is generally established on two features, both of which are realized fully in this scene: a resemblance of the space-time continuity that viewers are used to as a norm from the experience of the real world, which infuses the long take with "an anticipation of unmanipulated integrity" (Gibbs and Pye 8); and "sustained looking," which contradicts the way the viewers' gaze is commonly manipulated by either continuity editing or the various types of montage (15). The fluidity of camera movement as it follows Bond both promises integrity of content, which immediately enhances the weight of the scene, and preserves the viewers' attention to it. With the visual aid of the setting and the metaphysical load it carries, it provides viewers with a glimpse of the ultimate truth about their own nature, i.e. the inevitability of passing away. Bond's actions place the value of life in question, both his own and that of his target, as he effectively operates in an area where the boundaries between the dead and the living are blurred. Both the fate of the living and the return of the dead, as symbolized in the "Day of the Dead" in general as well as in the way the holiday is featured as a narrative trope in this scene, are meant to be disquieting and, as such, more engaging realizations that directly allude to viewers' own reality. Bond himself embodies the concept of death being brought down to the size of man: without losing the larger-than-life quality that is distinctive of the character throughout the franchise, he removes his skeleton mask when he is ready to proceed with the assassination, revealing that the true face of death is indistinguishable from the face of a normal living person; the underlying message being that, essentially, everyone is both alive and dead at the same time, only they do not realize it. The flow of the camera underscores this feeling: viewers follow a kind of continuous action as they would do if they were actually present, but at the same time occupying physically unnatural positions, such as high above the ground and of course remaining invisible to the characters. In this manner, they are effectively placed in the same position as the eerily omnipresent souls of the deceased, who are considered to be the invisible participants in the "Day of the Dead."

On a final note and similar to iQue Viva Mexico!, the use of the "Day of the Dead" in Spectre is also an example of the way cinema production realizes the 
transcultural dynamics of a holiday otherwise built on solid ethnic foundations, and even drives it forward. Andrew Chesnut and David Metcalfe note that the depiction of the "Day of the Dead" in Spectre, in addition to the increasing popularity of the holiday in the US, contributed to the reviving interest in this tradition. In fact, following the success of the film, real-life "Day of the Dead" parades have been organized in Mexico City; ${ }^{10}$ the imagery of the "Day of the Dead," as Chesnut and Metcalfe note, is now "an able ambassador for Mexico's cultural heritage around the globe." The contribution of Spectre to this situation further asserts the power of cinema to commercialize and globalize a cultural product with an already inherent attractiveness, thus actively affecting aspects of the viewers' reality. Besides, within this spirit of commercialization, cinema has generally shown interest in the cultural character of various ethnic groups; at the same time, as Brandes notes, tourism may in fact prove to be a factor that helps perpetuate local ritual performances instead of becoming one that contributes to their demise (70).

\section{LEE UNKRICH AND ADRIAN MOLINA'S COLORFUL AFTERLIFE}

Whereas ¿Que Viva Mexico! and Spectre use the "Day of the Dead" as a thematic chapter, Lee Unkrich and Adrian Molina's animated film Coco is exclusively about this particular holiday, and the film's success is an opportunity to explore its full impact to the audience. In contrast to the use of the holiday by Eisenstein to complete what he understood as the essence of his Mexican mural, and by Mendes as yet another location for Bond's international missions, Coco is "uniquely situated in a line of Disney ventures in Latin America combining policy and storytelling" (Castro 33). The massive success of Coco is an indication that the type of cultural immersion of audiences that Disney aimed for is, to a great extent, well-executed. The film uses the adventure of the main character, a boy named Miguel with a strong desire to become a musician, to highlight the "love shared amongst family" (Castro 33), thus managing to recreate the roots of the "Day of the Dead," as described earlier in the present article, and at the same time create a highly commercial product that appeals to wide global audiences. Positive reviews of the film include statements that it builds a "bridge of understanding among cultures" (Encalada) and that "Hollywood finally redeemed itself" for the stereotypical misrepresentations of Mexicans on film (Rose). Considering the obvious as much as financially understandable fact that the creators, and Disney in general, had a global outlook when putting Coco together, it

10 There has been considerable international press coverage of these parades, especially in 2016, which was the first time they were organized after the release of the film in 2015. Indicatively, see Jack Shepherd's article published on 27 October 2016 in the online edition of The Independent, which notes that even the original props and wardrobe from the film was to be used that year in the Mexico City parade. 
seems that the film managed to massively draw international audiences to cinemas, largely owing to the appealing transcultural quality that the "Day of the Dead" emits.

Disney went to great lengths to keep the film both appropriate and faithful to the background theme of the story. The company invested itself in making it work not only financially, but also aesthetically and culturally. In spite of Disney's initial marketing-related miscalculations ${ }^{11}$ and the fact that it proved to be a demanding production for a number of reasons, the overall result was both commercially successful and critically praised. In fact, the directors themselves claimed in an interview with Terry Gross that it took six years for the film to be completed, and their purpose was for "Latinos to see themselves on screen represented in a way that they can be proud of and in a way that reflects the things that they value about their culture and they value about their families." In addition to that, despite his fears about the reception of the film by Latinx audiences (Ugwu), Unkrich also noted in an interview with Brendon Connelly that he and his co-director were very proud about the way they "depicted Mexican culture and the Latino community." In their cited interviews, the directors do not seem to distinguish between Mexican and Latinx communities when referring to the audience that would reasonably have a cultural affiliation with the "Day of the Dead." The creators casted "a long list of Latinx voices" for the characters, as well as renowned artists from the Chicano art scene in Los Angeles for the artwork of the movie (Castro 34). Combined with a solid box office performance ${ }^{12}$ and a generally positive critical reception, this demonstrates the fact that the creators managed to bring to the surface the inclusive nature of the "Day of the Dead" and address the wider audience with it.

Technology was a key factor in visualizing on screen the communal cultural experience that the "Day of the Dead" represents. This is also true for both ; Que Viva Mexico! and Spectre, although the results in each case were substantially different: apart from using the technique of deep focus, Eisenstein was eager to experiment with the newly introduced technology of sound; and Mendes created the impression of unified space and time through an elaborate invisible editing of successive shots. Coco, on the other hand, showcases Disney's abilities and how far the quality of animation has gone in the past decades. Reviews often cite the meticulous attention

${ }^{11}$ Disney received massive backlash by the Latinx community after the company tried to trademark the phrase "Day of the Dead" / "Día de los Muertos" (Agredano-Lozano 79; Rose; Castro 33; Rodriguez; Ugwu). In addition to that, their decision to show the twenty-minute short movie Olaf's Frozen Adventure right before Coco in its initial screenings did not fare well either. Possibly an attempt to draw family audiences to cinemas using an already established product due to concerns about the universal appeal that Coco would have, this move was also received negatively by audiences and critics, with Disney being accused of "cynical marketing" (Kyriazis). There could have been indeed many more ways for the project to get derailed: brown-facing, for example, has been noticed to happen in Disney animation in the past (Aldama 7-8), and when the famous cartoonist Lalo Alcaraz was asked to join the production of Coco as a cultural consultant, he directly asked if there was going to be any brown-facing in the movie with regard to voice acting (qtd. in Castro 33-34; qtd. in Gomez).

${ }^{12}$ Elizabeth Castro mentions that Coco is among the most profitable films of all time in Mexico (34). 
to detail during production; Unkrich, for instance, describes how Miguel's fingers while playing his guitar were accurately reproduced from videos of real guitarists, so that he would be shown playing with maximum believability (Connelly). The film has also been praised for the quality of its color and visual depth, with its "living and breathing" settings being compared to the quality of those created by the acclaimed Japanese animation film company Studio Ghibli (Harrison). The result of these efforts is an example of visualizing a kind of imagined reality that would probably have been inaccessible otherwise: compared to Eisenstein's deep focus that brought the dead and the living to a productive clash, and Mendes's long take which extended cinematic space and time outside the screen, technology in Coco speaks to audiences by creating a version of the afterlife that is emotionally comforting and pleasurable, thus addressing the thorny issue of death with an inviting kindness. The movie touches on the theme of death with a sincerity and directness which seem to be more frequent in children's films (Collin), addressing a truth of life that is inevitably common for all viewers alike, regardless of descent.

Perhaps the most important technical parameter in the animation technique of Coco is the use of color. It is important to stress the fact that this is the only movie out of the three presently discussed that actually recreates the place where souls linger after death. Therefore, the use of color had to remain faithful to the extravagant aesthetics of the actual holiday itself, and at the same time to establish both the distinction between the world of the living and the world of the dead; this is achieved by the rich, but generally coherent, visual palette which is maintained throughout the film. Traditionally, color in film has been viewed in two opposite ways, i.e. either as a factor that enhances realism due to its "aura of authenticity," or as a means to escape realism and represent fantasy owing to its "wide range of signifying possibilities" (Costa 333-334). Although this normally refers to live action cinema, where both the signification and the use of color are quite differently understood compared to animation, it is also important to consider the fact that Coco has an important real-life referent as its main theme: getting it right means establishing ties with aesthetic levels connected with cultural and ethnic identity. Audience immersion in Coco works partly because colors are successfully associated with this aesthetic reality; the way warm and cool colors are combined in the same palette, building on the colorful festivities of the actual holiday, not only bridges effectively the two worlds portrayed in the film, but also reconciles, in a way, the two opposing views of film color that Costa describes: the recognizable realism of the colors used in the actual holiday blends smoothly with a culturally acceptable way for representing the imaginary world of the dead.

\section{CLOSING REMARKS}

The "Day of the Dead" has come both to transcend its original geographical and cultural boundaries, as well as to expand its variety of cultural significations, without losing its strong and recognizable originally Mexican, and Latinx at large, cultural imprint. Being a recurrent source of creativity and inspiration, the holiday 
obviously offers itself as the background for lavish aesthetic explorations, not always related to the folklore specifically, as well as a metaphor for transgression. The religious, visual and emotional themes of the holiday as described earlier, all playing with the concept of offering a peek to the-otherwise inaccessible to the living-land of the dead, effectively place participants in multiple positions: boundaries between conditions of being (faith-related or secular), unusually festive visual interpretations of the macabre and contrasting emotions, all dissolve under the combined weight of a deeper need for transgression and the excitement of experiencing the other side of things. These themes eventually serve as much wider, even primordial signifiers of spatial otherness, i.e. bridges that connect this world with the world of the dead as the ultimate "somewhere-else," therefore engaging participants to an experience of immersion that promises a temporary transference, which may be spiritual, but nonetheless operates through the natural human senses.

Considering this transgressive nature of the "Day of the Dead," its encounter with cinema has been a fortunate one, at least with regard to the three films presently discussed. Inscribed on the Representative List of the Intangible Cultural Heritage of Humanity by UNESCO in 2008, the holiday already has something universally human at its core, without surrendering or compromising its narrower ethnic origins and immediate audience. This universality is the point of crossover with cinema as a form of mass entertainment that represents a massively exported and globally circulated artistic product. A film works by enabling its narrative world to unfold based on its own self-sustained credibility that viewers accept for the duration of filmwatching; a successful filmic world creates some affectual connection with viewers, so that the latter invest their emotions-or at least their attention-to that world and let themselves be absorbed by the spatio-temporal flow of the narrative. In similar ways, David Carrasco describes the ability of festivals that are based on the "Day of the Dead," thus capitalizing on its affectual attraction, to "temporarily rivet human attention onto an alternate world;" the spirit of such festivals, Carrasco continues, is able to "transform our experience of time and place thereby 'transplanting' us, during these nights of wonder, danger and stunning symbols, into another section of our cosmos" (4). In order to show aspects of this alternate world, regardless of individual creative goals, films that feature the "Day of the Dead" for close to a century so far have been thematically varied, aesthetically extravagant and technically stunning; and film history will be grateful for this, as it should be with anything that contributes to making good movies. 


\section{WORKS CITED}

Agredano-Lozano, Felipe. “Death in L.A.: Días de Los Muertos, a Living Celebration.” ReVista: Harvard Review of Latin America 13/3 (Spring 2014): 78-80. https://revista.drclas.harvard. edu/book/death-la. Accessed 20 Mar. 2020.

Aldama, Frederick Luis. "Introduction: Putting the Pop in Latino/a Popular Culture." The Routledge Companion to Latinalo Popular Culture. Ed. Frederick Luis Aldama, Routledge, 2016. 1-19.

Brandes, Stanley. Skulls to the Living, Bread to the Dead: The Day of the Dead in Mexico and Beyond. Blackwell, 2006.

Bugeja, Nicholas. "A Multitude of Meanings: The Long Take: Critical Approaches, ed. John Gibbs \& Douglas Pye." Review of The Long Take: Critical Approaches. Eds. John Gibbs \& Douglas Pye. Senses of Cinema 90 (Mar. 2019) http://www.sensesofcinema.com/2019/book-reviews/ a-multitude-of-meanings-the-long-take-critical-approaches-ed-john-gibbs-and-douglaspyel. Accessed 12 Apr. 2020.

Carrasco, David. “The Paradox of Carnival." ReVista: Harvard Review of Latin America 13/ 3 (Spring 2014): 2-6 https://revista.drclas.harvard.edu/book/death-la. Accessed 20 Mar. 2020.

Castro, Elizabeth. "When Coco Feels like Home: Film as Homenaje." Review of Coco, dir. Lee Unkrich \& Adrian Molina. The Harvard Kennedy School Journal of Hispanic Policy 30 (2018): 33-38. ProQuest, https://search.proquest.com/docview/2187897395.

Chesnut, Andrew, \& David Metcalfe. "Meet Mexico's Trinity of Death-Day of the Dead, Santa Muerte, and Catrina Calavera." \#FolkloreThursday, 25 Oct. 2018, http://folklorethursday. $\mathrm{com} /$ folklife/meet-mexicos-trinity-of-death-day-of-the-dead-santa-muerte-and-catrinacalaveral. Accessed 5 May 2020.

Chinita, Fátima. "Sergei Eisenstein as Seen by Peter Greenaway: A Dialectic Representation of an (Anti-)Great Film Director.” Life Writing 16/2 (2019): 177-193. Taylor and Francis Online, doi: 10.1080/14484528.2019.1548251.

Coco. Dir. Lee Unkrich \& Adrian Molina, performances by Anthony Gonzalez, Gael García Bernal \& Benjamin Bratt, Walt Disney Pictures, 2017.

Collin, Robbie. "Children Need the Truth about Death.” The Sydney Morning Herald, 26 Jan. 2018, https://www.smh.com.au/entertainment/movies/children-need-the-truth-about-death20180119-h0l8my.html. Accessed 5 Mar. 2020.

Connelly, Brendon. “Lee Unkrich Interview: Directing Coco.” Den of Geek! 19 Jan. 2018. ProQuest, https://search.proquest.com/docview/1989114122. Accessed 4 Apr. 2020.

Costa, Maria Helena Braga e Vaz da Costa. "Color in Films: A Critical Overview.” Crítica Cultural 6/1 (2011): 333-346, https://repositorio.ufrn.br/jspui/handle/123456789/19307. Accessed 19 Dec 2017.

Eisenstein, Sergei. “First Outline of Que Viva Mexico!.” The Film Sense, by Sergei Eisenstein. Ed. Jay Leyda, trans. Jay Leyda, Meridian, 1957. 251-255.

EnCalada, Javier. “Movie Review: Pixar’s Coco Is a Fiesta.” Fraser Coast Chronicle, 7 Dec. 2017, https:// www.frasercoastchronicle.com.au/news/movie-review-pixars-coco-is-a-fiesta/3273776/. Accessed 19 Apr. 2020.

Gibbs, John, \& Douglas Pye. “Introduction 1: The Long Take-Critical Approaches.” The Long Take: Critical Approaches. Eds. John Gibbs \& Douglas Pye, Palgrave Macmillan, 2017. 1-26. 
Gomez, Luis. “Oscars 2018: How SDSU Alumnus Lalo Alcaraz Helped Coco Feel Mexican.” The San Diego Union-Tribune, 5 Mar. 2018, https://www.sandiegouniontribune.com/opinion/ the-conversation/sd-meet-lalo-alcaraz-san-diego-state-alumnus-worked-on-coco-20180305htmlstory.html. Accessed 19 Apr. 2020.

Gross, Terry. “Coco Filmmakers Explore the 'Connection to Loved Ones Past.” Fresh Air, 10 Jan. 2018. ProQuest, https://search.proquest.com/docview/1986225087. Accessed 10 Apr. 2020.

Harrison, Charlotte. “Coco Review.” Den of Geek, 19 Jan. 2018, https://www.denofgeek.com/movies/ coco-review-2/. Accessed 6 May 2020.

"Indigenous Festivity Dedicated to the Dead." UNESCO-Intangible Cultural Heritage, https://ich. unesco.org/en/RL/indigenous-festivity-dedicated-to-the-dead-00054. Accessed 18 Apr. 2020.

IrazÁbal, Clara, \& Grace R. Dyrness. "Promised Land? Immigration, Religiosity, and Space in Southern California." Space and Culture 13/4 (Aug. 2010): 356-375. SAGE Journals, doi:10.1177/1206331210374147.

Kyriazis, Stefan. "Frozen Short Removed from Coco Screenings: Audience Backlash Forced Disney to Let It Go?” Express, 4 Dec. 2017, https://www.express.co.uk/entertainment/films/887334/ Frozen-Olaf-sequel-short-REMOVED-from-Coco-screenings-Disney-Let-It-Go. Accessed 9 May 2020.

Marchi, Regina M. Day of the Dead in the USA: The Migration and Transformation of a Cultural Phenomenon. Rutgers UP, 2009.

Menard, David George. "Toward a Synthesis of Cinema-A Theory of the Long Take Moving Camera, Part 1.” Offscreen 7/8 (Aug. 2003). ProQuest, https://search.proquest.com/ docview/2064799094.

Montes de Oca, Rosa Isela Aguilar. "The Day of the Dead: One Ritual, New Folk Costumes, and Old Identities." Folklore: Electronic Journal of Folklore 66 (2016): 95-114. doi: 10.7592/ FEJF2016.66.aguilar.

Neale, Steve. "Introduction 2: The Long Take-Concepts, Practices, Technologies, and Histories." The Long Take: Critical Approaches. Eds. John Gibbs \& Douglas Pye, Palgrave Macmillan, 2017. 27-41.

Noble, Andrea. “Seeing through ;Que Viva México!: Eisenstein's Travels in Mexico." Journal of Iberian and Latin American Studies 12/2-3 (2006): 173-187. Taylor and Francis Online, doi: 10.1080/14701840601085022.

Olaf's Frozen Adventure. Dir. by Kevin Deters \& Stevie Wermers, performances by Josh Gad, Idina Menzel \& Kristen Bell. Walt Disney Animation Studios, 2017.

O’Mahony, Mike. Sergei Eisenstein. Reaktion Books, 2008.

¡Que Viva Mexico!. Dir. by Sergei M. Eisenstein, 1931.

Robertson, Robert. Eisenstein on the Audiovisual: The Montage of Music, Image and Sound in Cinema. Tauris Academic Studies, 2009.

Rodriguez, Cindy Y. "Day of the Dead Trademark Request Draws Backlash for Disney." CNN, 11 May 2013, https:/edition.cnn.com/2013/05/10/us/disney-trademark-day-dead/index. html. Accessed 22 May 2020. 
Rose, Steve. “Coco: The Pixar Film That Defies Donald Trump's Anti-Mexican Rhetoric.” The Guardian, 15 Jan. 2018, https://www.theguardian.com/film/2018/jan/15/coco-the-filmthat-defies-trumps-anti-mexican-rhetoric. Accessed 16 Apr. 2020.

Salazkina, Masha. In Excess: Sergei Eisenstein's Mexico. U of Chicago P, 2009.

Shepherd, Jack. "James Bond: Mexico City to Hold First Day of the Dead Parade Thanks to Spectre." The Independent, 27 Oct. 2016, https://www.independent.co.uk/arts-entertainment/films/ news/james-bond-spectre-mexico-city-day-dead-parade-a7382471.html. Accessed 7 Jun. 2020.

ShujaA, Kenya J. “Día de los Muertos (Day of the Dead).” The SAGE Encyclopedia of African Cultural Heritage in North America. Eds. Mwalimu J. Shujaa \& Kenya J. Shujaa, SAGE, 2015. 358359. SAGE Knowledge, doi: 10.4135/9781483346373.n113.

Sinclair, Upton. "Dear Comrade [Smirnov]." 19 Mar. 1932. Sergei Eisenstein and Upton Sinclair: The Making and Unmaking of Que Viva Mexico!. Eds. Harry M. Geduld \& Ronald Gottesman, Indiana UP, 1970. 305-310.

Smith, Paul Julian. "Letter from Mexico City." Film Quarterly 67/2 (2013): 57-58. JSTOR, doi: $10.1525 /$ fq.2014.67.2.57.

Spectre. Dir. Sam Mendes, performances by Daniel Craig, Christoph Waltz \& Léa Seydoux, B24, 2015.

Tотаro, Donato. "Visual Style in M. Night Shyamalan's 'Fantastic' Trilogy: The Long Take." Offscreen 7/11 (Nov. 2003). ProQuest, https://search.proquest.com/docview/2064799140.

Udden, James. "Child of the Long Take: Alfonso Cuaron's Film Aesthetics in the Shadow of Globalization.” Style 43/1 (Spring 2009): 26-44. ProQuest, https://search.proquest.com/ docview/220119566.

Ugwu, Reggie. "How Pixar Made Sure Coco Was Culturally Conscious." The New York Times, 19 Nov. 2017, https://www.nytimes.com/2017/11/19/movies/coco-pixar-politics.html. Accessed 22 May 2020.

Vassilieva, Julia. "Sergei Eisenstein’s ;Qué Viva México! Through Time: Historicizing Value Judgement." Continuum 24/5 (Oct. 2010): 693-705. Taylor and Francis Online, doi:10.10 80/10304312.2010.505336. 